\title{
A Study of an English for Academic Purposes Course
}

\author{
Mohammad Zohrabi \\ (The University of Tabriz, Iran) \\ Parilah M. Shah \\ (Universiti Kebangsaan Malaysia, Malaysia) \\ Melor M. Yunus \\ (Universiti Kebangsaan Malaysia, Malaysia) \\ doi:10.7575/aiac.alls.v.3n.2p.11
}

\section{Abstract}

English for General Purposes (EGP) is a foundation course which should be taken by all the undergraduate students at the University of Tabriz, Iran. However, the EGP course cannot meet the students' objectives and needs. Evidently, it has some shortcoming and the results of the study indicate that it not only has lost its credibility but also has failed to achieve its goals. This study strives to investigate the different dimensions of this course in order to come up with some solutions to its betterment. The participants consist of current and ex-students, language and subject instructors. The result of the study indicates that there are many factors which are involved in decreasing the quality of the EGP course. The goals of the EGP course need to be determined and redefined. It is hoped that this research could shed some fresh light on the betterment and modification of this course.

\section{Introduction}

Any educational program needs to be studied from time to time in order to ensure that it is functioning as effectively as possible (Parilah \& Zohrabi, 2008). To this end, program evaluation attempts to evaluate every aspect of an instructional program or course of study in order to find out its virtues and weaknesses. By identifying the weaknesses of a course, the researchers try to find some solutions in order to compensate for them (Lynch, 2003). Then, they endeavor to modify the course through recommending some new methods and materials. However, there are times that require a course of study to be changed totally. Therefore, in order to materialize a comprehensive study of a course, it is necessary to gather as much information as possible. Meanwhile, in order to verify the data, the information about the 
course should be obtained through different methods and different sources. In this way the validity and reliability of data can be enhanced substantially (Brown, 2001).

Therefore, the purpose of the present study is to investigate the perceptions of the students and instructors toward the English for General Purposes (EGP) course. The reason that the present researchers intended to study this course relates to the problem which have decreased the effectiveness of it. For instance, the EGP course does not meet the students' present needs and objectives. The students have lost confidence in this course and only take it as an obligatory course to gain credit rather than to enrich their general English. Most of the instructors either have a vague idea or totally are unaware of the objectives of this course. The main problem is that the undergraduate students take the EGP course, study it and ultimately obtain a pass mark. Yet, they have many deficiencies in reading, writing, listening and speaking. An obvious example of the problem of the students is that they cannot study their ESP (English for Specific Purposes) courses 1 and 2 as efficiently as possible. That is, the EGP course does not prepare the students to perform effectively in their ESP courses.

In the following sections, the curriculum constructs which were selected for investigation will be presented and explained. Then, the methodology which was used to collect and analyze data will be elaborated on. After that the result of the study will be put forward and discussed.

\section{Curriculum constructs}

In order to implement our program evaluation more coherently, the present researchers selected 12 curriculum constructs: objectives, attitudes, time, students and instructors, needs analysis, classroom activities, materials, study skills, language skills, vocabulary, grammar and assessment (Zohrabi, 2008). These 12 constructs helped the researchers to investigate every aspect of the EGP course as completely as possible. Clearly, every program of study consists of many factors which influence it in one way or another. Without identifying these constructs, it would have been quite arduous to study the EGP course. These 12 constructs helped the present researchers to investigate all the elements involved in this program one by one and step by step. 


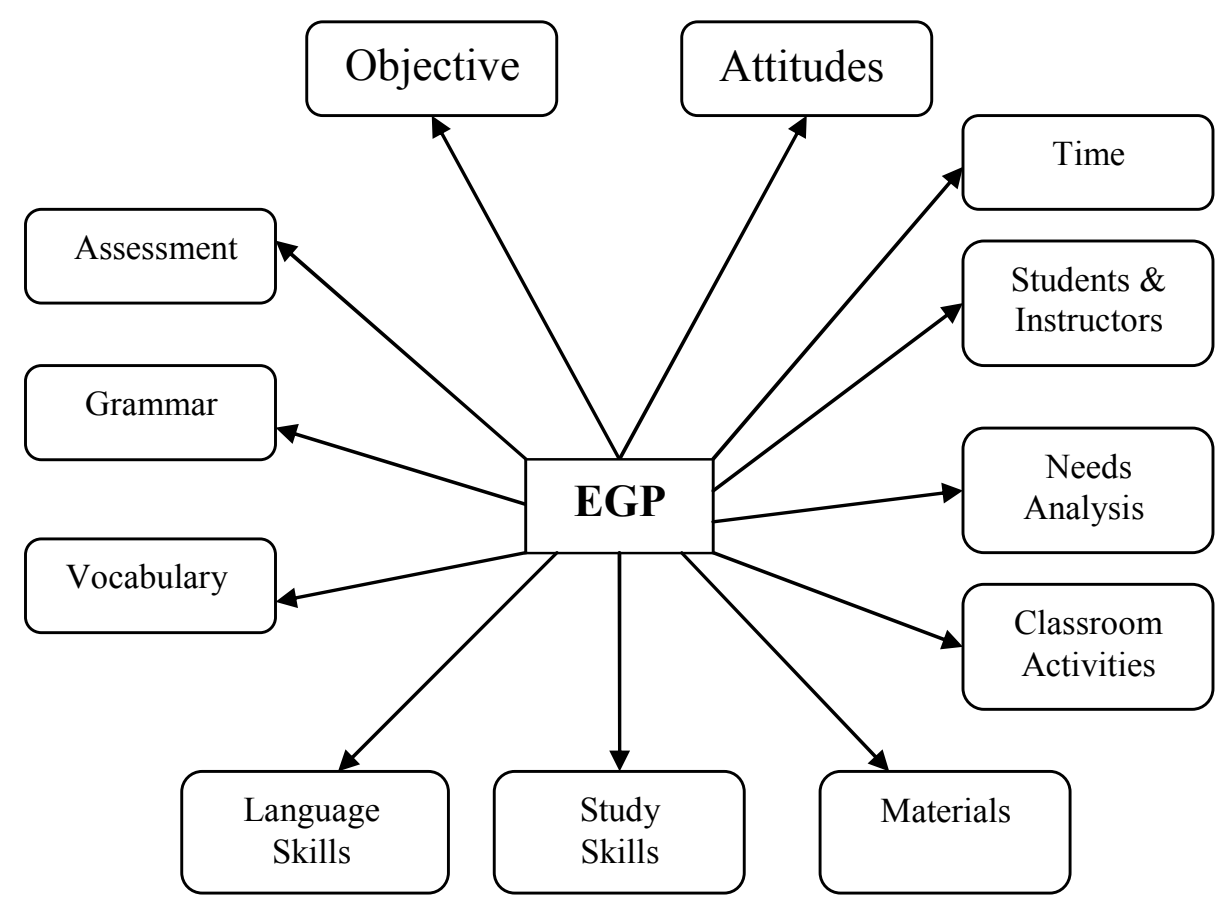

Figure 1: EGP course and its elements

It is safe to say that the present study can be likened to a medical diagnosis. That is, in order to diagnose an illness, a physician first takes history of a patient (asks several questions from the patient about his/her illness). Then, the physician strives to diagnose the illness through various procedures: blood or urine test, x-ray, CAT scan, MRI and other imaging examinations. Finally, the physician comes up with some cure through prescribing some medications, surgery, diet, exercise and so on. Similarly, the first step of the present study was to obtain the whole picture of the EGP course through studying the students' and instructors' perceptions. Then, the second step was to investigate the problems that were involved in this course. Finally, the third step was to put all the data together after thorough investigation in order to come up with some solutions. In this way, the researchers could recommend some solutions in order to modify the EGP course and compensate for its deficiencies.

\section{Program evaluation}

It can be proposed that evaluation is a process in which great amounts of data are gathered through various procedures from different sources. Then, this information is interpreted to make some important decisions based on the research results. These decisions might require a change and effect a drastic alteration in the outline and process of a language program instruction. All these efforts are made to the betterment of a course of study and bringing 
about some satisfactory results (Zohrabi, 2009). Murphy (1985, p. 4) argues that "evaluation should be an integral part of the working of the curriculum to ensure that what is done is worthwhile, necessary and sufficient." Jordan (1997, p. 85) contends that "The purpose of evaluation is to collect information systematically in order to indicate the worth or merit of a program or project ... and to inform decision making both from the point of view of development and the end product." However, evaluation is not merely the process of gathering information. It is studying the shortcomings of a course of study in order to see whether the objectives have been achieved, so that to make some decisions according to that information. Nunan (1999, p. 185) asserts that "The data resulting from evaluation assist us in deciding whether a course needs to be modified or altered in anyway so that objectives may be achieved more effectively." It should be noted that evaluation is not a one-way process in which only the learners are judged by outsider researchers. It is, however, a multi-way process in which the learners, the learning process, the teachers, and the whole teachinglearning process are scrutinized.

Program or course study can be approached from different perspectives. In order to investigate a program, the researcher should determine the means or tools of gathering data. For instance, data can be obtained through questionnaires, interviews, classroom observations and so on (Lynch, 1996). Meanwhile, the researcher should identify the informants in order to obtain reliable information. Therefore, the researcher can gain the necessary information from learners, teachers, course designers, program staff and so on.

The following program evaluation model has been proposal by Alderson (1996, p. 274). In this outline he mentions some actual ways of implementing the evaluation process. He has categorized the stages as follows:

1- Planning
2- Implementing
3- Interpreting
4- Reporting
5- Using
6- Evaluating $\quad\left\{\begin{array}{l}\text { Purpose: Why? } \\ \text { Audience: Who for? } \\ \text { The researcher: Who? } \\ \text { Content: What? } \\ \text { Method: How? } \\ \text { Timing: When? }\end{array}\right.$


The following figure illustrates in detail the process of conducting the present study:

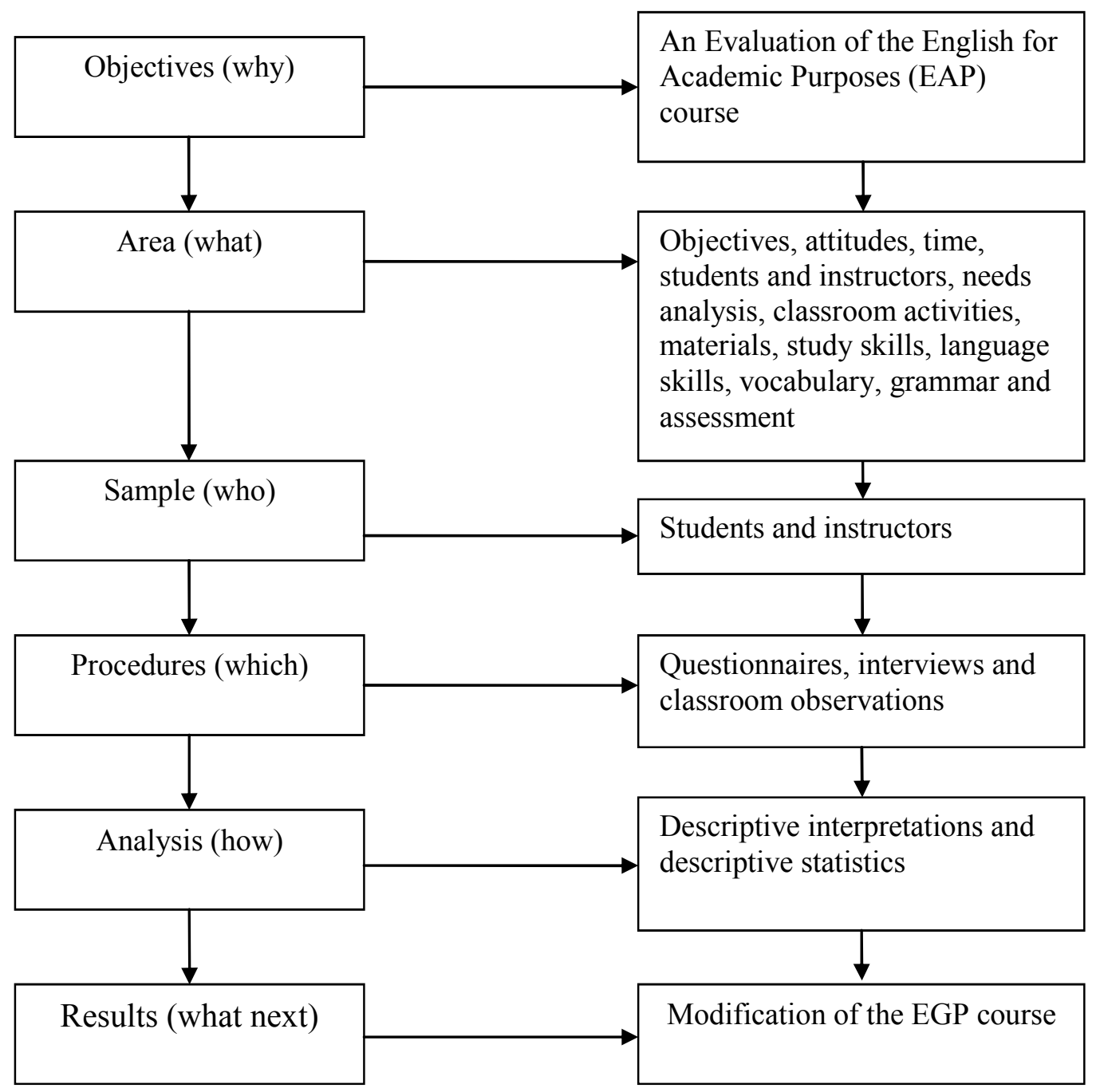

Figure 2: The overall frame of the study

\section{Design and methodology}

The design of this study is a mixed method design. The reason that the mixed method design was opted for this study is that it uses both quantitative and qualitative data. Meanwhile, by using both quantitative and qualitative data, we can triangulate our data and hence boost the validity and reliability of the research (Creswell, 2003). Therefore, in order to conduct research on the EGP course, both quantitative (closed-ended questionnaire) and qualitative (interviews and classroom observations) data were gathered. 
A rather similar questionnaire was given directly to the current students $(n=360)$, ex-students $(n=360)$ and language instructors $(n=16)$. The questionnaire items consisted of 76 closedended questions for which respondents had to choose the appropriate option based on their perceptions. The format of the items was Likert-type form: strongly disagree, disagree, unsure, agree and strongly agree. Meanwhile, the questionnaire had one open-ended item to which the participants had to provide their own answers. It should be mentioned that since the questionnaire items were in the field of ELT (English Language Teaching), they were not given to subject instructors to be filled out.

In order to validate the data, from the 16 language instructors 12 experienced instructors were chosen to be interviewed. Also, 12 subject instructors who taught the ESP courses 1 and 2 at their respective departments were chosen to be interviewed. These 12 subject instructors were selected based on their experience and from each of the 12 faculties of the University of Tabriz one instructor was chosen. Meanwhile, 36 current EGP students were selected to participate in the interview. These current students were selected based on their University Entrance Exam results: one below average, one average and one above average. That is, from each of the 12 faculties, three current students were selected. Additionally, from each of the 12 faculties of the University of Tabriz, three ex-students were chosen. These students who totally comprised 36 students were selected based on their EGP scores: one below average, one average and one above average.

Furthermore, in order to obtain first-hand experience of the EGP classes, the researchers observed 12 classes at each of the faculties of the University of Tabriz. These classes belonged to the language instructors who were interviewed. Each of these 12 classes was observed for several times $(4,5$ or 6 times) in order to obtain the intended data. Totally, two methods were used in order to gather the classroom data. First, a checklist form was prepared by the researchers and the important points were included. Therefore, during the classroom observations the lack or existence of these important points was ticked. Second, in addition to the checklist form, the researchers tried to write down the important classroom activities and occurrences. The following figure indicates the process of data collection: 


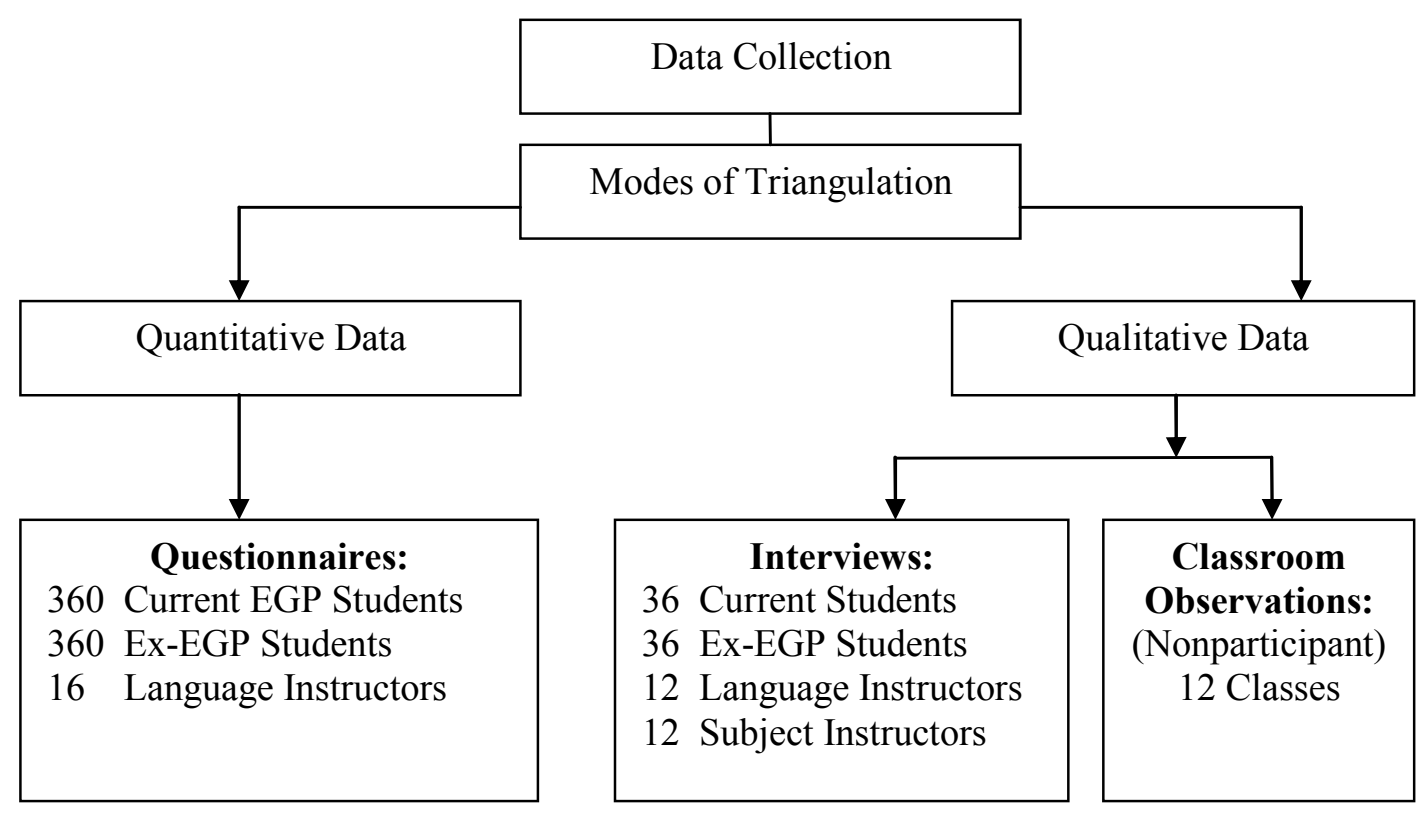

Figure 3: Data collection procedure

Later, the closed-ended questionnaire data which were in numerical form were analyzed through frequency counts and percentages. Meanwhile, the last item of the questionnaire which was open-ended and in text form, the recorded interview data which had been transcribed, and the classroom observation notes were analyzed in descriptive and interpretative form.

\section{Findings}

In order to ease the process of analysis, the data were analyzed in terms of the 12 evaluation constructs. This section presents the findings of the study:

\section{1- Objectives}

Apparently, the result of the study indicates that most of the instructors and students do not clearly know the objectives of the EGP course. Seemingly, there is a huge gap between the students and the course's goals. Most of the students prefer verbal interaction and free discussion in the classroom. However, because of the time limitation most of the instructors merely focus on reading skill. The English Department at the University of Tabriz does not provide the instructors with the teacher's manual. It is because the Ministry of Education has not identified the objectives of the EGP course. 


\section{2- Attitudes}

Since the EGP course does not meet the students' objectives and needs, most of the students hold a low attitude toward it. The students do not find the EGP course interesting and useful for their future studies or workplace needs. Meanwhile, the instructors do not take this course seriously too.

\section{3- Time}

Evidently, three hours in a week during one semester is not enough to master general English. Since the time allocated to the EGP course is short, the instructors cannot dedicate equal time for each skill and consequently concentrate on reading skill which ultimately bores the students. Meanwhile, because of the shortness of time, the instructors cannot carry out different tasks and only do their textbook exercises.

\section{4- Students and instructors}

Since a placement test is not given to the students at the beginning of the semester, the EGP classes consist of heterogeneous number of students. The mixed-ability classes, consequently, create problems not only for the students but also for the instructors. It seems that most of the EGP classes are instructor-centered rather than being learning-centered. The instructors dominate the EGP classes and mostly use traditional methods of language teaching.

\section{5- Needs analysis}

Seemingly, needs analysis has never been carried out at the University of Tabriz in order to determine the students' needs. It appears that there are huge differences between the students' needs and what the EGP course offers.

\section{6- Classroom activities}

The result of the study indicates that the teaching methods used in the EGP classes are not appropriate. Most of the instructors try to do their textbook exercises instead of performing different tasks. There is no revision of the previous materials. There is a lack of group or pair work. The activities that are performed do not promote creative responses.

\section{7- Materials}

Clearly, the amount of materials used in the EGP classes is not enough. The activities of the textbooks do not encourage the students to have communicative practice and free use of the 
language. The EGP classes are not equipped with audio-visual aids. Sometimes, the textbooks used are either too easy or too difficult for the students' levels.

\section{8- Study skills}

Most of the students emphasize that the study skills are not taught to them. The EGP course does not bring about independent and autonomous language learners. There are no self-access learning centers either at each of the 12 faculties or at the university. Since the study skills are not taught, the students lack enough self-confidence to study independently and fulfill their course requirements.

\section{9- Language skills}

Apparently, the only skill which is practiced in the EGP classes is the reading skill. The writing, speaking and listening skills have been forgotten and ignored totally. Most of the instructors speak the Persian language instead of English in the EGP classes. Meanwhile, most of the students either lack the ability or have low self-confidence to speak English.

\section{0- Vocabulary}

Most of the students have shortage of vocabulary in the general English. The new vocabulary items are not presented in a purposeful way or in appropriate context. The new vocabulary items are not practiced or repeated in subsequent lessons or units.

\section{1- Grammar}

The students' textbooks lack appropriate grammar exercises. The grammar exercises do not represent the realistic use of the language. There is no correspondence between language forms and the real use of language.

\section{2- Assessment}

Most of the students emphasized that they were not aware of how their instructors were going to grade them. The students were worried about their final exams. Most of the instructors did not give mid-semester exam. The ex-students maintained that their EGP scores were given based on only their final exam results. The instructors usually do not explain their assessment criteria at the beginning of the semester to the students. The exam questions usually consist of discrete point items. The students are barely asked to provide their own answers either in written or spoken form. 


\section{Discussion}

In this section it is attempted to present and discuss the findings of the study in terms of the 12 evaluation constructs.

\section{1- Objectives}

The ministry of Education should prepare a comprehensive syllabus for the EGP course and determine its objectives. The instructors and students need to be aware of the goals of this course.

\section{2- Attitudes}

The instructors should make every effort to promote the students' attitudes toward the EGP course. This can be done through making the course more interesting to the students. The instructors should try to enrich and reward the positive points about the EGP course and eliminate the negative cones.

\section{3- Time}

It goes without saying that the time allocated to the EGP course should be increased. The undergraduate students need more exposure to the EGP course in order to learn it effectively.

\section{4- Students and instructors}

In order to maintain a balance among the different students with different proficiency levels, it is better to give a placement test and place the students based on their levels in appropriate classes.

\section{5- Needs analysis}

It seems necessary that the University of Tabriz curriculum developers carry out a needs analysis and redefine the syllabus based on the students' needs, wants, lacks and desires.

\section{6- Classroom activities}

Classroom activities should be organized around task-based activities and promote communicative skills and strategies as well as free use of language. Classroom activities should be diverse and varied in order to motivate the students and prevent boredom. 


\section{7- Materials}

The materials used for the EGP course should be interesting, suitable and based on different student tastes. It is better for each branch of science (humanities, engineering, medicine, science and literature) a different textbook to be used.

\section{8- Study skills}

It is believed that the University of Tabriz needs to offer an independent course under the study skills in order to prepare the students for their academic courses.

\section{9- Language skills}

The instructors should have enough time in order to practice all the four language skills. All the skills are related to each other in one way or another.

\section{0- Vocabulary}

The newly presented vocabulary items should be repeated in different contexts and subsequent units in order to be retained.

\section{1- Grammar}

The students need both grammatical explanations and ample exercises. The purpose of the grammar exercises should promote free use of language.

\section{2- Assessment}

The assessment criteria should be explained to the students at the beginning of the course. The instructors should consider the students' classroom activities when assigning their final grades. Meanwhile, the instructors should include mid-semester exam in order to prepare the students for the final exam.

\section{Conclusion and implications}

Program evaluation endeavors to find out the weaknesses of a course of study. However, it is the officials and administrators who should want to implement the results. Without inducing any changes in the course, the study would be a waste of time, energy and resources. Therefore, the researchers, teachers, students and administrators need to try to apply and implement the results of the study for the betterment of their courses. Certainly, the present study has wide implications for researchers interested in the fields of EGP, ESP and EAP. 
Also, this study can be significant to teachers, postgraduate students, course designers and program staff.

\section{References}

Alderson, J.C. (1996). Guidelines for the evaluation of language education. In J. C. Alderson \& A. Beretta (Eds.). Evaluating second language education (pp. 274-304). Cambridge: Cambridge University Press.

Brown, J. D. (2001). Using surveys in language programs. Cambridge: Cambridge University Press.

Creswell, J. W. (2003). Research design: Qualitative, quantitative, and mixed methods approaches. Second ed. Thousand Oaks, CA: Sage.

Jordan, R. R. (1997). English for academic purposes: a guide and resource book for teachers. Cambridge: Cambridge University Press.

Lynch, B. K. (1996). Language program evaluation: Theory and practice. Cambridge: Cambridge University Press.

Lynch, B. K. (2003). Language assessment and program evaluation. Edinburgh: Edinburgh University Press.

Murphy, D. F. (1985). Evaluation in language teaching: assessment, accountability and awareness. In J.C. Alderson (Ed.). Evaluation (pp. 1-17). Oxford: Pergamon.

Nunan, D. (1999). Research methods in language learning. Eighth printing. Cambridge: Cambridge University Press.

Parilah M. Shah \& Zohrabi, M. (2008). The process of implementing program evaluation. Proceedings of International Conference on the Education of Learner Diversity: Managing Diversity in Educational and Community Settings. 377-388. Universiti Kebangsaan Malaysia, 26-27 August 2008.

Zohrabi, M. (2008). Researching into curriculum components. Journal of Pan-pacific Association of Applied Linguistics, 12(2): 49-69.

Zohrabi, M. (2009). An evaluation of English language curriculum components. In N. Othman and S. Govindasamy (Eds.). English and Asia (pp. 117-132). Malaysia: IIUM Press. 